\title{
Mobile Money, the Symbolism of Physical Money and Emerging Dynamics in Social Relationships among Low-Income Earners in Kenya
}

\author{
Kennedy Munyua Waweru ${ }^{1}$ \\ ${ }^{1}$ School of Business and Economics, The Co-operative University of Kenya, Kenya \\ Correspondence: Kennedy Munyua Waweru, School of Business and Economics, The Co-operative University \\ of Kenya, P.O. Box 24814-00502 Karen-Kenya Nairobi, Kenya. E-mail: kwaweru@cuck.ac.ke
}

Received: February 17, 2017

Accepted: March 11, 2017

Online Published: March 26, 2017

doi:10.5539/ijbm.v12n4p178

URL: https://doi.org/10.5539/ijbm.v12n4p178

\begin{abstract}
Kenya which is considered a leader of digitization of money in the form of mobile money in the developing world has been compared in some studies with Sweden, world leader in digitization of financial transaction among its residents. Despite the progress in digitization of financial transactions witnessed in many countries, opinion is still divided on whether full digitization of financial transactions is feasible. This study examines the symbolism of the physical money among low-income earners in Kenya a key variable to be considered in any move towards full digitization of financial transactions. The study surveyed 750 low-income households across Kenya and conducted focus groups. Findings indicate that Kenyans consider physical money as symbol of purchasing power that is irreplaceable by mobile money. They view mobile money as a complementary financial transactions facilitator especially for money transfer and not a replacement of cash. Findings also suggest that the advent of mobile money is be associated some increase in the degree of disconnection in personal interactions in social relationships. It also emerged that mobile money has facilitated continuity of rotating saving and credit associations in cases of mobility resulting from employments or other factors.
\end{abstract}

Keywords: digital money, mobile money, physical money

\section{Introduction}

The definition of digital money is quite broad because it encompassing all non-cash and non-paper value exchange transactions. In deeded, included in this definition are credit/debit/charge cards, direct transfer, prepaid cards, electronic funds transfer (EFT) and a wide array of other innovations in electronic means of value exchange such as mobile money (Thomas, Vernet \& Gann 2014). Digitization refers to the dematerialization of tangible physical or fiat money into an intangible electronic form. For the last 30 years, the world has seen a progressive digitization of money and payment systems. Some countries such as Singapore set out as early as 1998 to completely digitize it money in 10 years by adopting an electronic legal tender, the Singapore Electronic Legal Tender (OECD, 2002). Singapore however continues to issue bank notes which by the year 2012 increased $6 \%$. The level of digitization of money in Sweden on the other hand is argued to be the highest in the world. Cash transaction account for only three percent of total transactions in Sweden as compared to seven percent of all transactions in the USA and nine percent in the Eurozone. It is projected by the Stockholm's Royal Institute of Technology that Sweden may become the first cashless country by 2030 (Mark 2015). Many other countries (Note 1) have enacted legislations geared towards promoting digitization such as restricting large value transactions to digital means (Beretta, 2014; Ejiofor \& Rasaki, 2012).

Amongst the developing countries, the leverage on mobile telephone system infrastructure by Kenya has resulted in an exponential growth in the level of digitization of financial transactions to levels that rival those of developed countries despite its less developed digital infrastructure. Data from the Communication Authority of Kenya (CAK) indicates that during the period December 2015 to June 2016 mobile money subscriptions stood at 26.3 million, the number of mobile money transactions and value grew by $13 \%$ and $18 \%$ to stand at 375.8 million transactions and Ksh 950 billion (USD 9.5 billion (Note 2) ) respectively (CAK, 2015; CAK, 2016). Mas \& Radcliffe (2011) note that M-Pesa one of the mobile money systems in Kenya now handles more transactions domestically than Western Union does globally. Mas et al., (2015) conducts a comparative analysis of 
digitization of financial transaction in Sweden and Kenya and note that despite having a comparatively less diversified digital ecosystem, Kenya's economy, as well as Sweden's, has digitized in a significant way, which has undoubtedly had a profound effect on financial participation by citizens. Despite the progress in digitization of financial transactions witnessed in many countries, opinion is still divided on whether full digitization of financial transactions (elimination of cash transactions) is feasible.

Proponents of full digitization of money such as Rogoff (2014) contend that, granted the role of paper currency in facilitating tax evasion and illegal activity, and given the persistent and perhaps recurring problem of the zero bound on nominal interest rates, it is time to consider more proactive strategy for phasing out the use of paper currency. Other benefits of digitization from various studies have also been cited in support of digitization. Among these benefits is increased financial inclusion. Waweru and Kamau (2017), find that the introduction of mobile money in Kenya was accompanied by a significant increase in the number of low-income earners using formal financial services in banks and savings and credit co-operative societies (SACCOs). This view is supported by GSMA (2015) in case studies involving seven mobile money operators in five countries and a host of other earlier studies such as Batista and Vicente, (2013), Donovan (2012), Mas and Mayer (2011).

Increased incentive to save has also been cited by Karlan et al., (2014) as a benefit associated with digitizing payments. This argument is also supported by Mbiti, and Weil (2014), Muthiora (2015) in Kenya, Nandhi, (2012) in India, Severino, Tonderai and Life (2015) in Zimbabwe, Lal and Sachdev (2015) in several countries among a host of other individual country specific studies. Digitization of money has also been associated with enhanced speed and delivery time in payments and remittances (World Bank, 2014a). Extant literature shows that remittances both international and domestic have increasingly played a significant role in financial development and it has been argued that digitization facilitates enhanced efficiency and speed in remittances. Orozco et al., (2010) argues that as remittance volumes have grown, so have providers of payment services. This assertion is in line with the position by Aggarwal et al., (2011) who using data on remittance flows to 109 developing countries over more than 30 years finds a significant and robust link between remittances and financial development. This view is also supported by country specific studies of among others Chowdhury (2011) in Indonesia. Evidence on any causal link between remittances and economic growth is however divergent and inconclusive (Catrinescu et al., 2009 and Barajas et al., 2009).

It has been suggested that digitizing payments can also lead to significant cost savings in the long term both for large payments like government social transfers and individuals viewed in terms of travel costs and time savings. The savings attributable to digital transfers for low-income earners have for instance been estimated in Niger to be equivalent to an amount that can feed a family of five for a day based on average agricultural wages (Aker et al., 2013). The cost savings benefit has been supported by Rashmi Pillai (2016), World Bank, (2014b) and Ejiofor \& Rasaki, (2012). Another benefit put forth is increased security, and reduced transaction anonymity associated with cash. Varjavand, R. (2011) posits that liquidity and transactional anonymity associated with cash are critical to the functioning of the underground economy and Wright et al., (2014) suggests that the introduction of EFT payments has been associated with reduction in crime and leakage of revenue in the United States of America.

Opponents of full digitization of money argue that the pursuit is an illusion and that, it is unlikely that cash transactions will be eliminated. Baretta (2014) argues that cash still plays a symbolic role in post-industrial societies, a role that becomes particularly visible in a situation of economic turmoil, characterized by generalized distrust in the banking and financial system. He notes that despite the increased digitization of money, many countries considered to have relatively advanced digital infrastructural ecosystems have also seen an increase in the notes and coins in circulation (Note 3). Cash also generates benefits for society that are not directly linked to its payments function. These benefits are summarized in the characteristics cash that include being universal, generating trust, being efficient and connecting people. Lepecq (nd) contends that although several alternative payment instruments can match one or two attributes of cash, none can offer its full range of benefits. It has been argued that full digitization of money will take away seigniorage revenue (Note 4) Kaminska (2013). In a review of the book "The End of Money: Counterfeiters, Preachers, Techies, Dreamers- and the Coming Cashless Society" by David Wolman, O'Grady (2012) states that seigniorage revenue to the US government was US\$ 70 billion in 2011. It is also contended that while seigniorage revenue is not the primary source of revenue for governments, it is none the less significant. A counter-argument to the assertion that digitization of money is associated with increased security given by Katharine, Kaffenberger, and Zimmerman (2015) bring to the fore the issues of attendant risks in mobile money from a customer's perspective. Risks arising from their study include fraud that targets customers, inadequate data privacy and protection, inability to transact due to network downtime and insufficient agent liquidity. 
Central to the divergence of opinion on the issue of complete digitization of money is the question of the symbolism of physical money. If physical money still hold some symbolic value to the users, then despite the any of the benefits advanced for full digitization of money, it is unlikely that cash will phased out until the issue of its symbolism is addressed. The first issue that this paper investigates is the symbolism of physical money (cash) for low-income earners in Kenya. Mobile money has been in existence for less than 10 years. Being a relatively new technological innovation, it has not been evaluated from a wide variety of approaches and as such the literature on mobile money tends to be celebratory. A strong consensus only emerges from a diversity of views and approaches Sunstein (2003). Technological innovations have accompanying positive or negative social impacts and mobile money is not an exception. As such, the second issue the paper examines is the emerging dynamics in social relationships among low-income earners in Kenya around the use of mobile money. Kusimba, et al., (2015) study social networks of mobile money in Kenya and find that mobile communities are fundamentally changing Kenyan social life. They suggest that ceremonies create geographically dispersed social networks of more superficial participation; mobile ROSCAs (Note 5) micro-coordinate social action and emotional affect without physical connection.

\section{Methodology}

The study conducted a survey which was supplemented with focus group discussions. The population of Kenya was estimated to be 47,251,447 in 2016 when the survey was carried out. The target population of the study comprised adult persons over 18 years of age (estimated to be $50.5 \%$ of the total population in Kenya) living below the poverty line (estimated to be approximately $33 \%$ ) as per the last poverty headcount carried out in the year 2006. The poverty line is defined by Kenya National Bureau of Statistics (KNBS, 2007) at Ksh 1,562 and 2,913 per month in rural and urban settings respectively which translates to Ksh 52 per day for rural adult persons, (adjusted for inflation this equals Ksh 69.15 or $0.7 \mathrm{USD}$ at current exchange rates of $1 \mathrm{USD}=101 \mathrm{KSh}$ ). The equivalent poverty line for (KSh 97.1) urban areas adjusted for inflation is Ksh 126.98 or USD 1.25. Mobile phone penetration, mobile network quality, literacy levels and a host of other factors differ between the two segments of the population (Michaels, 2011; CAK, 2016). Due these and other unique social cultural characteristics in the different parts of the country, the population was stratified into urban and rural areas. Urban areas are defined as locations with more than 10,000 persons. Based on this definition, there are 101 urban locations in Kenya as per (KNBS, 2010). Following the approach suggested by UN (2005) for household surveys, the sample size determined to be 650 households but was adjusted upwards by $15 \%$ to 750 households to cover for non-responses. Granted that 68 percent of Kenyans live in urban areas while 32 percent of the population live in rural areas, using proportionate sample size allocation, 510 households were drawn from urban areas while 240 households came from rural areas. The households were drawn from 75 Locations of in 27 Sub-Counties of 10 randomly selected counties in Kenya. Data was collected using detailed questionnaires from April 25, to May 13, 2016 and while the focus group discussions were conducted on September 13, 2016. To test our hypotheses, we conducted Chi Square tests.

\section{Results}

\subsection{Description of Respondents}

The representation of gender in the study sample was 48.8 percent males and 51.2 percent females. 24.8 percent of the respondents ages lay between 18 - 25 years, 35.7 percent between 26 - 35 years, 18.4 percent between 36 45 years, 10.6 percent between 46 - 55 years, while the rest were aged above 55 years. Married persons comprised 59.6 percent of the study sample, 7.7 percent of whom were polygamously married while 32 percent were not married, widowed persons on the other hand were 2.3 percent. Separated, divorced and cohabiting persons each comprised less than 2 percent each. 15.7 percent of the respondents had no formal education. 35.7 percent respondents had some undergone primary education, 32.9 had completed secondary education while 14.7 percent had undergone tertiary education. The nature of employments of the respondents was diverse. Unemployed persons constituted 22.4 percent of the respondents, 54 percent of these unemployed persons, derived their subsistence from family members, 44 percent from occasional hired labour while 2 percent received support from government social protection remittances. 17.2 percent of the respondents were farmers, 14.5 percent were manual labourers, street vendors, tailors, hairdressers, household workers ranged from 2 to 5 percent. Mechanics, messengers, watchmen conductors and retirees comprised between 1 and 2 percent of the respondents. Mobile phone ownership amongst the respondents was 90 percent, 78 percent of the mobile phone owners had basic phones while 22 percent owned a smart phone. 66 percent of those without mobile phones accessed mobile phone services from relatives and 34 percent from friends or neighbors. 


\subsection{Mobile Money Account and Usage}

The study first sought to find out the level of awareness of mobile money services providers by the low-income earners. The level of awareness was generally high for this segment of the population at 99 percent for Mpesa, 72 percent for Airtel money, 57 percent for Orange money, 56 percent for Equitel money, 34 percent for Yucash, 26 percent for Mobicash and 11 percent for Tangaza money. Findings showed that 87.3 percent of all the surveyed respondents had registered with mobile money services provider(s), most of them were registered with Mpesa at 88 percent, Airtel at 6 percent, Equitel money which is the latest entrant at 5 percent, Tangaza money at 3 percent, Orange money at 1 percent and the rest at less than 1 percent. Asked about the importance of mobile money accounts to their finances 43.5 percent of the low-income earners with mobile money accounts considered it to be extremely important to their finances 19.5 percent considered mobile money accounts important and 28 percent considered the mobile money accounts as somewhat important. Results on the types of services accessed using mobile money accounts revealed that 91 and 86 percent use their mobile money account to receive and send money respectively, 79 percent use it for airtime top-ups and 69 percent use it to save money. Those without mobile money accounts gave varied reasons for not having such accounts. Generally, those without mobile money accounts accounted to 11.7 percent of all the surveyed low income earners. 34.5 percent of this group stated that they did not need a mobile money account. Those who did not have mobile money accounts because of lacking mobile phones were 27.1 percent. Lack of identification documents which is a key know your customer (KYC) requirement in the registration processes was cited as a reason by 12.3 percent of this group while 17.2 percent said they did not trust mobile money accounts.

\subsection{The Effect of Mobile Money on the Symbolism of Physical Money/Cash}

The form digitization that this group interacted with mostly was mobile money since only 39.6 percent of the low-income earners surveyed had formal bank accounts and only 43 percent of this group with bank accounts used their bank accounts frequently. On the other hand, 87.3 percent of all the respondents had mobile money account. Further, over 90 percent of low-income earners with mobile accounts used them frequently. To find out the effect of mobile money on the symbolism of physical money or cash, we first explored the extent to which the respondents considered it important to have physical money over digital money. Our findings indicate that 25.8 percent of all the low-income earners considered it very important to have cash over mobile money. 31.8 percent considered it important to have physical money over mobile money while 15.7 percent were indifferent. Those who considered having physical money somewhat unimportant were 19.5 percent while the category who felt it was unimportant constituted 7.2 percent of the respondents. When we split, the sample based on dimension of rural/urban locations, our findings were similar with those of the full sample. In fact, the low-income earners who considered it important to very important to have physical cash over mobile money in rural and urban locations were 56.9 percent and 58 percent respectively compared with 56.8 percent for the full sample. When the sample was split based on gender, the results were slightly different from those of the full sample. The category of males who felt that having physical cash was important to very important were 56.1 percent of males compared to 59.1 percent of females. Generally, the number of low-income earners who considered it important to very important to have physical money over mobile money were found to be significantly more than those considered it unimportant to indifferent at $5 \%$ level of significance for the full sample $(\mathrm{Chi}[1]=10.8$, $\mathrm{p}$-value $=$ 0.001 ), when the, sample was split along rural (Chi [1] $=4.595$, p-value $=0.03$ ) urban locations (Chi [1] $=12.507, \mathrm{p}$-value $=0.00)$ and also when the sample was split based on gender, males (Chi $[1]=5.011$, $\mathrm{p}$-value $=0.025$ ) and females $($ Chi $[1]=12.1, \mathrm{p}$-value $=0.01)$. Results also indicated that the number of females who considered having physical money important to very important were significantly more than those males (Chi [1] $=271.69$, $\mathrm{p}$-value $=0.00$ ).

When the low-income earners were asked to what extent the advent of mobile money had affected the significance of having physical money, 33.6 percent stated that the advent of mobile money had affected their perception of the significance of having physical money 66.4 percent felt that the advent of mobile money had not changed their perception of the significance of having physical cash. The number of low-income earners who stated that the advent of mobile money did not have any effect of their perception the significance of having physical money were significantly more than those that said that mobile money influenced their perception of having physical money $(\mathrm{Chi}[1]=79.474$, p-value $=0.00$ ). The results were similar when the sample was split based on gender. It was observed that 68.8 percent of males (Chi $[1]=51.338$, p-value $=0.00)$ and 63.2 percent of females $(\mathrm{Chi}[1]=25.679, \mathrm{p}$-value $=0.00)$ respectively did not change their perception of the significance of having physical money even after the advent of mobile money. Similar results were also observed when the sample was split based on urban/rural locations. In urban locations, 69.8 percent (Chi $[1]=79.689$, p-value $=0.00)$ and 58.9 percent $(\mathrm{Chi}[1]=8.134$, p-value $=0.04)$ of low-income earners stated that mobile money did not 
change their perception of the importance of having physical money.

The reasons why the digitization of money into mobile money had not influenced the perception the of significance of holding physical cash by most low-income earners were explored through focus groups discussions. The discussions revealed that while most low-income earners considered mobile money accounts as safer value storage and saving instruments (69 percent regularly use mobile money accounts for this function), they did not envision situations where all their money was held in digital form. They felt the need to have some physical cash always and if at any time the physical cash was depleted, low-earners would convert some mobile money into cash. Asked why they felt the need to convert mobile money into cash when they had an option of transacting using mobile money, the issue of transaction fees featured prominently. Making transacting through mobile money wallets such as Lipa na Mpesa was considered costly compared to cash by the low-income earners. Survey results corroborated this because 91 percent and 86 percent of the low-income earners mainly used mobile money accounts to receive and send money respectively. For this function, mobile money accounts were considered cheaper and safer than other available means by the low-income earners. This finding agrees with Lepecq (nd) assertion that cash is the cheapest means of conducting transactions. The focus group discussions revealed that low-income earners considered mobile money a complimentary system of facilitating monetary transactions mainly money transfer and airtime purchase but not a replacement of physical money. Another reason coming out of the discussions was that mobile money in some instances made them feel a loss of purchasing power in cases of poor network, network downtime, and lack of float (insufficient liquidity by mobile money agents) especially in some rural areas where mobile money agents are few and far between. The finding of inability to transact in some areas due to incomplete digital ecosystem is in line with Katharine, Kaffenberger, and Zimmerman (2015). Mobile money was not considered to offer the same level of purchasing power as physical money therefore, cash was unrivalled by mobile money as a symbol of purchasing power.

Granted that results indicated that 69 percent of the respondents used mobile money accounts as value storage/saving devices, the influence of mobile money on saving habits was also investigated. Results indicated that 69.6 percent of the low-income earners felt that their saving habits had changed after they adopted the use of mobile money accounts while 30.4 percent felt that the adoption of mobile money did not change their saving habits in any way. Amongst those who felt that mobile money had changed their saving habits, $94 \%$ indicated that they saved more regularly after the adoption of mobile money while 5.8 percent indicated that they saved less regularly after they adopted the used of mobile money. The latter category indicated that they purchased airtime more often than before even when it was not very necessary and it would have been prudent to save. When the sample were split based on gender and on rural/urban dimensions the findings were not different form the full sample. Findings indicated that 95.7 percent of the males and 92.6 of females who said that the adoption of mobile money had changed their saving habits, saved more regularly after the adoption of mobile money. Amongst the category of urban dwellers whose saving habits had been changed by the adoption of mobile money, 94.2 percent indicated that they saved more regularly after the adoption of mobile money against 93.6 percent of rural dwellers.

\subsection{Mobile Money and the Emerging Dynamics in Social Relationship among Low-Income Earners}

Result from focus group discussions indicated that mobile money had affected social relationships in several ways. The study found out that before the advent of mobile money, low-income earners felt obligated to visit relatives and friends in cases of death, sickness, and social events such as weddings mainly because the means of sending money were not as cheap and fast as mobile money. Similarly, those who worked distances away from their family also felt the need to visit them at least once per month as they took home money for subsistence. These visits allowed them to have regular personal interactions and contact in their social relationships. There was a consensus that mobile money had resulted in some reduction number of times low-income earners felt obligated to visit relatives and friends. Once they sent them money they felt it was not necessary to visit them. That fact that they could keep in contact on phone notwithstanding, focus group discussants agreed that the advent of mobile money had led to some increase in the degree of disconnection in personal interactions in social relationships. Personal interactions with the extended family and friends in distant areas appeared to have been affected more than the nuclear family. It also emerged that demands/requests for financial assistance from relatives and friends have increased after the advent of mobile money. Previously, mobile phone ownership amongst the low-income earners was very low and as such, means of communicating such demands/requests were not easily accessible and even where they were accessible, the means of sending money were costly. This meant that such demands/requests were few. On the upside, there was a convergence of opinion among focus group discussants that mobile money facilitated easier means to provide support to relatives and friends during the social events by those who wished to provide such support. Providing subsistence and support in 
emergencies through mobile money is faster and has facilitated the provision of social protection from the relatives, government and Non-Governmental Organizations than was hitherto the case.

It emerged that mobile money has facilitated continuity of ROSCAs. These associations may be formed by family members, friends, workmates, neighbors, church members and other such associations that make people interact for some period. Most low-income earners have temporary employments the result of which most are mobile. Mobile money was found to facilitate the continuity of these associations because members need not exit because of job related mobility. They could continue making their contributions despite the distance, the result of which these social relationships are not broken. This finding is in concurrence the Kusimba, et al., (2015). The finding of continuity of ROSCAs from focus group discussions is corroborated by the survey findings that showed there was a significant increase in the ROSCAs after the advent of mobile money. Whether the increase was directly associated with the advent of mobile money or a coincidence in the general appeal for ROSCAs among Kenyans was not isolated by the study. What came out was that the mobile money facilitated the social relationships in ROSCAs to continue even after mobility of members dictated by employments or other reasons.

\section{Conclusions}

A conclusion from the findings of this study regarding the effect of mobile money on the symbolism of physical money suggests that low-income earners in Kenya consider having physical money or cash as more important than having mobile money. This category of Kenyans view mobile money as a complementary financial transactions facilitator especially for money transfer and not a replacement of cash. They consider physical money as symbol of purchasing power that is irreplaceable by mobile money and irrespective of having money in mobile many accounts, they must replenish their physical money from mobile money once it is depleted. This applies across gender and whether the low-income earners live in urban areas or rural areas. Despite the benefits cited for full digitization of financial transactions, any move towards this direction may only be successful after a shift in the symbolism of physical money among other factors has occurred. That notwithstanding, digitization of money in the form of mobile money in Kenya has been associated with a change in the saving habits of low-income earners. Significantly more low-income earners save more regularly after adopting the use of mobile money. Regarding the issue mobile money and emerging social relationships, findings suggest that advent of mobile money is associated some increase in the degree of disconnection personal interactions in social relationships. It also emerged that mobile money has facilitated continuity of ROSCAs in cases of mobility of members resulting from employments or other factors.

\section{References}

Aggarwal, R., Demirgüç-Kunt, A., \& Martínez Pería, S. (2011). Do remittances promote financial development?" Journal of Development Economics, 96(2), 255-264.

Aker, J., Boumnijel, R., McClelland, A., \& Tierney, N. (2013). How Do Electronic Transfers Compare? Evidence from a Mobile Money Cash Transfer Experiment in Niger. Tufs University Working Paper.

Barajas, A., Chami, R., Fullenkamp, C., Gapen, M., \& Montiel, P. J. (2009). Do workers' remittances promote economic growth?

Batista, C., \& Vicente, P. C. (2013). Introducing Mobile Money in Rural Mozambique: Evidence from a Field Experiment.

Beretta, E. (2014). Irreplaceability of cash and recent limitations to its use: Why Europe is off the track. in International cash conference on "The usage, costs and benefits of cash revisited" Deutsche Bundesbank, Dresden (D), 5-18.

CAK. (2015). Quarterly Sector Statistics Report, First Quarter of the Financial Year 2015/16. Nairobi: Communication Authority of Kenya.

CAK. (2016). Quarterly Sector Statistics Report, Fourth Quarter of the Financial Year 2015/16. Nairobi: Communication Authority of Kenya.

Catrinescu, N., Leon-Ledesma, M., Piracha, M., \& Quillin, B. (2009). Remittances, institutions, and economic growth. World Development, 37(1), 81-92.

Chowdhury, M. B. (2011). Remittances flow and financial development in Bangladesh. Economic Modelling, 28(6), 2600-2608.

Donovan, K. (2012). Mobile money and financial inclusion. In T. Kelly \& M. Minges (Eds.), Information and communication for development 2012. Washington, DC: World Bank. 
Ejiofor, V. E., \& Rasaki, J. O. (2012). Realizing the benefits and challenges of cashless economy in Nigeria: it perspective. International Journal of Advances in Computer Science and Technology, 1(1).

GSMA. (2015). Mobile Money for the Unbanked Case Studies: Insights, best practices and lessons from across the globe: (online) London: GSMA.

Kaminska Izabella. (2013). Why central banks should take charge of their digital currencies (online).

Karlan, D., Ratan, A. L., \& Zinman, J. (2014). Savings By and For the Poor: A Research Review and Agenda." Review of Income and Wealth 60(1), 36-78.

KNBS. (2007). Basic Report on Well-Being in Kenya. Nairobi: Kenya National Bureau of Statistics.

KNBS. (2010). Kenya 2009 Population and Housing Census Report. Nairobi: Kenya National Bureau of Statistics.

Kusimba, S., Chaggar, H., Gross, E., \& Kunyu, G. (2013). Social Networks of Mobile Money in Kenya. California: Institute for Money, Technology \& Financial Inclusion.

Lal, R., \& Ishan, S. (2015). Mobile Money Services - Design and Development for Financial Inclusion. Harvard Business School Working Paper No. 15-083.

Lepecq Guillaume (nd) Cash essentials beyond payments (online ) Paris: AGIS Consulting.

Mac, M. T., Diaz, A. R., Altai, H., O'Donnell, M., \& Ahmed, J. (2015). Money in the 21st Century-The Rise of the Digital Economy in Kenya and Sweden (Doctoral dissertation).

Mark, H. (2015) Sweden Is Developing the World's First Cashless Economy.

Mas, I., \& Radcliffe, D. (2011). Mobile Payments Go Viral: M-Pesa in Kenya. The Carpco Institute's Journal of Financial Transformation, 32, 169-181.

Mas, Ignacio and Colin Mayer. (2011). Savings as Forward Payments: Innovations on Mobile Money Platforms.

Matt O'Grady. (2012). Living without physical cash is already easy. But is digital money too abstract?

Mavhiki, S., Nyamwanza, T., \& Shumba, L. (2015). Impact of mobile banking on traditional banking Practices in Zimbabwe. International Journal of Economics, Commerce and Management Vol III No. 1.

Mbiti, I., \& Weil, D. N. (2014). Mobile Banking: The Impact of MPesa in Kenya. NBER Working Paper No. 17129.

Michaels, L. (2011). Better than cash: Kenya mobile money market assessment. United States Agency for International Development. New York: USAID.

Muthiora, B. (2015), Enabling Mobile Money Policies in Kenya Fostering a Digital Financial Revolution. Mobile for Development Impact.

Nandhi, M. A. (2012). Effects of Mobile Banking on the savings practices of low income users. The Indian Experience. Institute of Money, Technology and Financial Inclusion.

OECD. (2002). Singapore Electronic Legal Tender (SELT) A Proposed Concept. Low Siang Kok, in the Future of Money. (online) Paris: OECD. Available at The Future of Money.

Rashmi, P. (2016). Person-to-Government payments: Lessons from Tanzania's digitization efforts.

Rogoff, K. (2015). Costs and benefits to phasing out paper currency. NBER Macroeconomics Annual, 29(1), 445-456.

Thomas, L. D., Vernet, A., \& Gann, D. M. (2014). Digital Money: How Ready are Countries to Adopt? In DRUID Society Conference.

UN. (2005). Designing Household Survey Samples: Practical Guidelines. New York: United Nations.

Varjavand, R. (2011). Growing underground economy: The evidence, the measures, and the consequences. Journal of International Management Studies, 11(3), 133-142.

Waweru K. M., \& Kamau, J. W. (2017) The effect of mobile money on saving and money transfer practices for low-income earners in Kenya. Journal of Business Studies Quarterly, 8(3).

World Bank. (2014a). The opportunities of digitizing payments. (online) Washington: World Bank.

World Bank. (2014b). Financial Inclusion Data.

Wright, R., Tekin, E., Topalli, V., McClellan, C., Dickinson, T., \& Rosenfeld, R. (2014). Less Cash, Less Crime: 
Evidence from the Electronic Beneft Transfer Program." National Bureau of Economic Research. NBER Working Paper 19996.

\section{Notes}

Note 1. Belgium, Bulgaria, Czech Republic, Denmark, France, Greece, Hungary, Italy, Portugal, Slovakia, Spain have instituted cash restrictions on transactions by residents ranging from 1000 euros in France Italy and Portugal to 12,763 euros in Spain. (Barreta, 2014).

Note 2. The exchange rate at the time of the study was 1USD: 101Ksh.

Note 3. The Euro Area, Hong Kong, Japan, Russia, Singapore, Switzerland, United States all have seen an increase in the notes in circulation for the year 2008 to 2012 ranging from $0.68 \%$ Singapore to $3.51 \%$ in Hong Kong (see Baretta 2014).

Note 4. Seigniorage is the profit made by a government from the printing of money, literally the face value of the money minus the cost of physically making it.

Note 5. Rotating saving and credit associations.

\section{Copyrights}

Copyright for this article is retained by the author(s), with first publication rights granted to the journal.

This is an open-access article distributed under the terms and conditions of the Creative Commons Attribution license (http://creativecommons.org/licenses/by/4.0/). 